\title{
MSK1 regulates environmental enrichment-induced hippocampal plasticity and cognitive enhancement
}

\author{
Kate Karelina, ${ }^{1}$ Katelin F. Hansen, ${ }^{1}$ Yun-Sik Choi, ${ }^{2}$ A. Courtney DeVries, ${ }^{1}$ \\ J. Simon C. Arthur, ${ }^{3}$ and Karl Obrietan ${ }^{1,4}$ \\ ${ }^{1}$ Department of Neuroscience, The Ohio State University, Columbus, Ohio 43210, USA; ${ }^{2}$ Department of Pharmaceutical Science \& \\ Technology, Catholic University of Daegu, Gyeongbuk, Republic of Korea, 712-702; ${ }^{3}$ MRC Protein Phosphorylation Unit, School of Life \\ Sciences, University of Dundee, Dundee DD1 5EH, Scotland, United Kingdom
}

\begin{abstract}
Environmental enrichment (EE) has marked beneficial effects on cognitive capacity. Given the possibility that this form of neuronal plasticity could function via the actuation of the same cellular signaling pathways that underlie learning/memory formation, we examined whether the MAPK cascade effector, mitogen/stress-activated kinase 1 (MSK1), could play a role in this process. MSK1 functions as a key signaling intermediate that couples changes in neuronal activity into inducible gene expression, neuronal plasticity, and learning/memory. Here, we show that MSK1 is expressed in excitatory cell layers of the hippocampus, progenitor cells of the subgranular zone (SGZ), and adult-born immature neurons. MSK1 ${ }^{-1-}$ mice exhibit reduced spinogenesis and decreased dendritic branching complexity in hippocampal neurons, compared with WT mice. Further, in $\mathrm{MSKI}^{-1-}$ mice, progenitor cell proliferation within the SGZ was significantly reduced and, correspondingly, the number of immature neurons within the dentate gyrus was significantly reduced. Consistent with prior work, $\mathrm{MSKI}^{-/-}$mice displayed deficits in both spatial and recognition memory tasks. Strikingly, cognitive enhancement resulting from a 40-d period of EE was markedly reduced in $\mathrm{MSKl}^{-/-}$animals. $\mathrm{MSKI}^{-/}$mice exhibited reduced levels of EE-induced spinogenesis and SGZ progenitor proliferation. Taken together, these data reveal that MSK1 serves as a critical regulator of hippocampal physiology and function and that MSK1 serves as a key conduit by which enriching stimuli augment cellular plasticity and cognition.
\end{abstract}

[Supplemental material is available for this article.]

The structural and functional blueprint that gives rise to the neuronal circuitry of limbic and cortical structures imparts an incredible degree of cellular plasticity. A central feature of these circuits is to capture and convert short-term changes in synaptic activity into long-term alterations in synapse function, which is thought to underlie learning and memory. In addition, these circuits also appear to be capable of integrating over much longer time scales (i.e., days to months), thus allowing the functionality of these structures to be shaped by relatively subtle changes in the environment. Consistent with this idea, in animal studies, alterations in the external environment which enhance sensory stimulation (i.e., environmental enrichment; EE), or conversely, environmental conditions that deprive the animal of stimuli for many weeks, have been found to profoundly affect/shape cognitive capacity (van Praag et al. 2000; Bruel-Jungerman et al. 2005; Bianchi et al. 2006). At a cellular level, EE triggers an increase in the generation and integration of adult-born neurons into the granule cell layer (GCL) of the hippocampus and increases dendritic branching complexity and synapse formation in excitatory neurons of the hippocampus (Kempermann et al. 1997, 1998; van Praag et al. 2000; Faherty et al. 2003). Further, reduced sensory stimulation leads to a decrease in progenitor proliferation and dendrite branch patterns, which likely results in the wellcharacterized increase in depression and reduced cognitive capacity (Silva-Gomez et al. 2003; Bianchi et al. 2006; Ibi et al. 2008). Importantly, retrospective analysis of humans exposed to psycho-

\footnotetext{
${ }^{4}$ Corresponding author

E-mail obrietan.1@osu.edu

Article is online at http://www.learnmem.org/cgi/doi/10.1101//m.025775.112.
}

social or behavioral enrichment appears to support the findings of animal studies (Cotman and Berchtold 2002; Agrigoroaei and Lachman 2011; Erickson et al. 2011).

Given that EE facilitates/augments cognitive capacity through a series of processes (i.e., synaptic connectivity, synapse formation) that also appear to underlie learning and memory, it is, perhaps, reasonable to hypothesize that these two temporally distinct forms of functional plasticity are mediated by similar intracellular signaling pathways. In line with this idea, we sought to examine whether signaling via the ERK1/2 and p38 effector kinase MSK 1 (mitogen- and stress-activated kinase 1 ) contributes to EE-evoked cognitive enhancement. The rationale for this examination is based on an extensive literature showing that ERK/ MAPK signaling plays a key role in late-phase, transcriptionally dependent LTP, which is thought to underlie memory formation (English and Sweatt 1997; Davis et al. 2000; Wu et al. 2006). Given that much of the transactivation potential of the ERK/ MAPK pathway is mediated by downstream effector kinases, MSK1 appears to be ideally positioned to affect neuronal plasticity (Wiggin et al. 2002; Soloaga et al. 2003). Along these lines, MSK1 functions as the dominant MAPK-activated cAMP response element binding protein (CREB) kinase (Deak et al. 1998; Arthur and Cohen 2000). Likewise, MSK1 has been shown to affect chromatin structure via the phosphorylation of histone $\mathrm{H} 3$ at Ser 10 and Ser 28 and via phosphorylation of the nonhistone chromosomal protein HMG-14 (Thomson et al. 1999; Soloaga et al. 2003). The functional ramifications of MSK1 on CNS physiology were underlined by work showing that neurotrophininduced expression of CREB-regulated genes is markedly depressed in MSK1-deficient neurons (Arthur et al. 2004). Further, 
MSK1-deficient mice exhibit significant deficits in learning and memory, which are associated with a reduction in the phosphorylation state of CREB and histone H3 (Chwang et al. 2007). Together, these data raise the prospect that MSK1 could play a key role in EE-evoked cognitive enhancement.

In this study, we employed a MSK1 mouse knockout model to assess the role of MSK1 in memory formation, hippocampal morphological plasticity, and EE-induced cognitive enhancement. We report that MSK1 $1^{-/-}$mice perform poorly on memory tasks. Moreover, morphometric analysis of mature hippocampal neurons revealed a marked reduction in dendritic branching complexity of $\mathrm{MSK}^{-/-}$mice and decreased subgranular zone (SGZ) progenitor cell proliferation. Of note, cognitive enhancement resulting from EE was attenuated in $\mathrm{MSK}^{-/-}$mice relative to wildtype (WT) littermates. Consistent with this, the effects of EE on progenitor cell proliferation and spinogenesis were blunted in $\mathrm{MSK}^{-/-}$mice. Together, these data reveal a central role for MSK1 in shaping both basal and inducible changes in cognitive capacity.

\section{Results}

\section{Generation of $\mathrm{MSKI}^{-/-}$mice}

The targeting construct for MSK1 has been described previously (Arthur and Cohen 2000), and genotyping was confirmed by PCR (Fig. 1A). Western blot analysis of biological replicates and immunohistochemistry further confirmed the absence of MSK1 expression in $\mathrm{MSK}^{-/-}$mice (Fig. 1A,D). Cresyl violet labeling
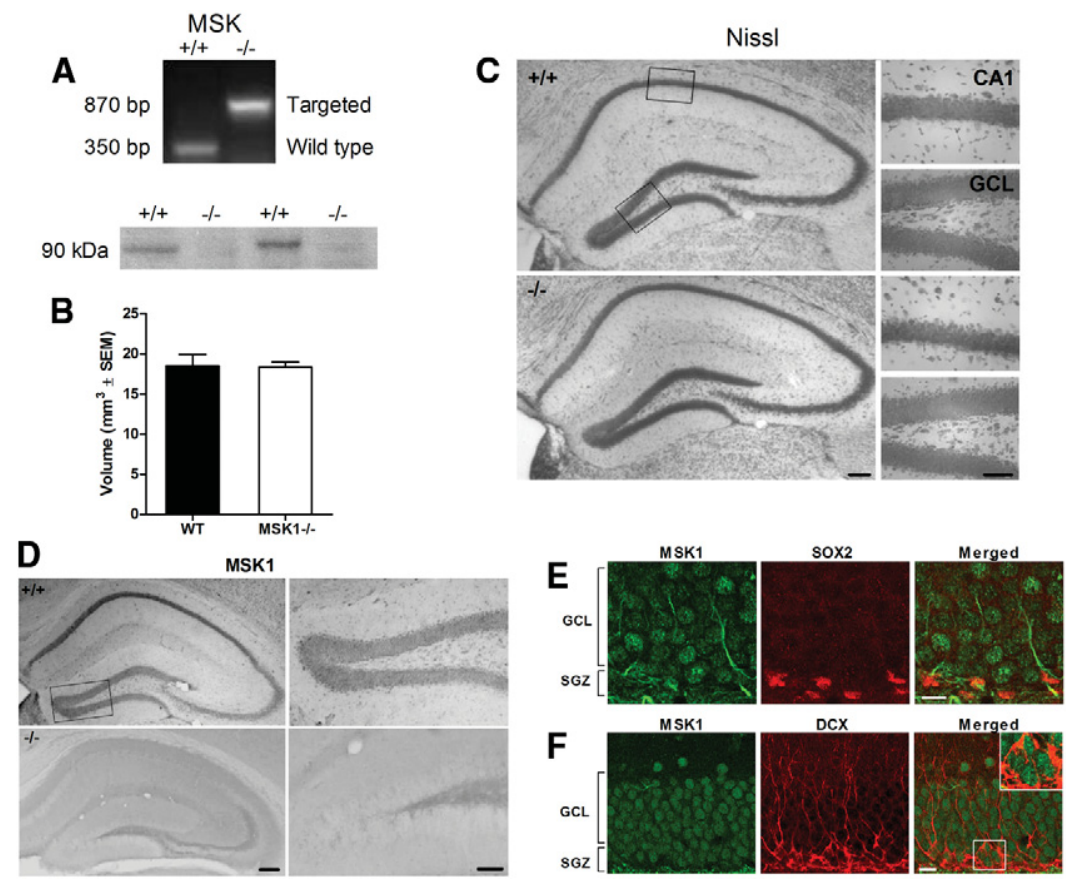

Figure 1. Generation of MSK1 $1^{-/-}$mice. $(A)$ Genotyping of MSK1 knockout $(-/-)$ and WT $(+/+)$ mice from tail biopsy samples and western blotting of biological replicates (two animals per condition) confirming the absence of MSK1 expression in $\mathrm{MSK}^{-/-}$mice. (B) Quantification of hippocampal volume from cresyl violet-stained tissue revealed no gross morphological differences in the hippocampus of WT and MSK1 ${ }^{-/-}$mice. (C) Representative cresyl violet-stained hippocampus images, scale $\mathrm{bar}=200 \mu \mathrm{m}$ (low-magnification images), $100 \mu \mathrm{m}$ (high-magnification images). (D) Immunohistochemical labeling detected MSK1 expression throughout the hippocampus of WT mice; MSK1 labeling was not detected in MSK1 ${ }^{-/-}$mice. $(E)$ In WT mice, within the subgranular zone of the dentate gyrus, relatively weak and limited MSK1 expression was detected in SOX2-positive stem/progenitor cells. $(F)$ Double labeling in WT mice revealed MSK1 expression throughout the GCL and in the doublecortin (DCX)-positive progenitor cells. Scale bar = $20 \mu \mathrm{m}$. (GCL) Granule cell layer; (SGZ) subgranular zone. revealed no gross morphological differences in the hippocampus of WT and MSK1 ${ }^{-/-}$mice, and hippocampus volume was not been reported in aged (9-mo-old) $\mathrm{MSK}^{-/-}$mice (Martin et al. 2011); however, at the 6- to 12 -wk developmental time point usere, a neurodegenerative profile was not detected. In WT mice, MSK1 expression was detected within both the granule cell layer and the SGZ of the dentate gyrus (Fig. 1E,F). Within (DCX)-positive immature neurons, whereas in the SOX2-positive stem/progenitor cells (Komitova and Eriksson 2004), relatively

\section{Dendritic morphology}

As part of our analysis of hippocampal physiology and function, Sholl analysis revealed striking differences between the hippocampal dendritic morphology of $\mathrm{MSK}^{-/-}$and WT mice. duced branching complexity of dendrites in the dentate gyrus GCL and the CA1/CA3 cell layers (Fig. 2A). The reduction in proximal apical region, which receives inputs from the Schaffer granule cells of the dentate gyrus). Further, MSK1 $1^{-/-}$mice exhibited a significantly reduced CA1 and CA3 dendritic spine density relative to WT mice, but no differences in GCL dendritic spine density were observed (Fig. 2B,C). Together, these data reveal that MSK1 plays a role in both arborization and spine density of hippocampal excitatory neurons.

\section{Progenitor cell proliferation and adult-born neurogenesis}

The observation that MSK1 is expressed in progenitor cells of the SGZ and in DCX-positive immature neurons (Fig. $1 \mathrm{E}, \mathrm{F})$ raises the possibility that MSK1 could regulate aspects of progenitor division and neuronal development. To examine whether MSK1 regulates progenitor cell proliferation, we immunolabeled for Ki-67, a marker of actively proliferating progenitor cells (Scholzen and Gerdes 2000). Representative photomicrographs and quantitative analysis revealed a marked reduction in the number of Ki-67-postive cells in the dentate gyrus SGZ (Fig. 3A). To determine whether these data point to a reduction in the total pool of progenitors, adjacent sections were also labeled for SOX2, a transcription factor expressed by neural progenitor cells. SOX2 labeling within the SGZ was not significantly different between WT and $\mathrm{MSK}^{-/-}$mice, indicating that MSK1 deletion reduced the proliferative capacity of progenitors, rather than the total number of progenitor cells (Fig. 3B). Finally, in order to examine whether the reduction in proliferating progenitor cells would result in fewer adult-born neurons, adjacent sections were also labeled for DCX. Compared to 
A
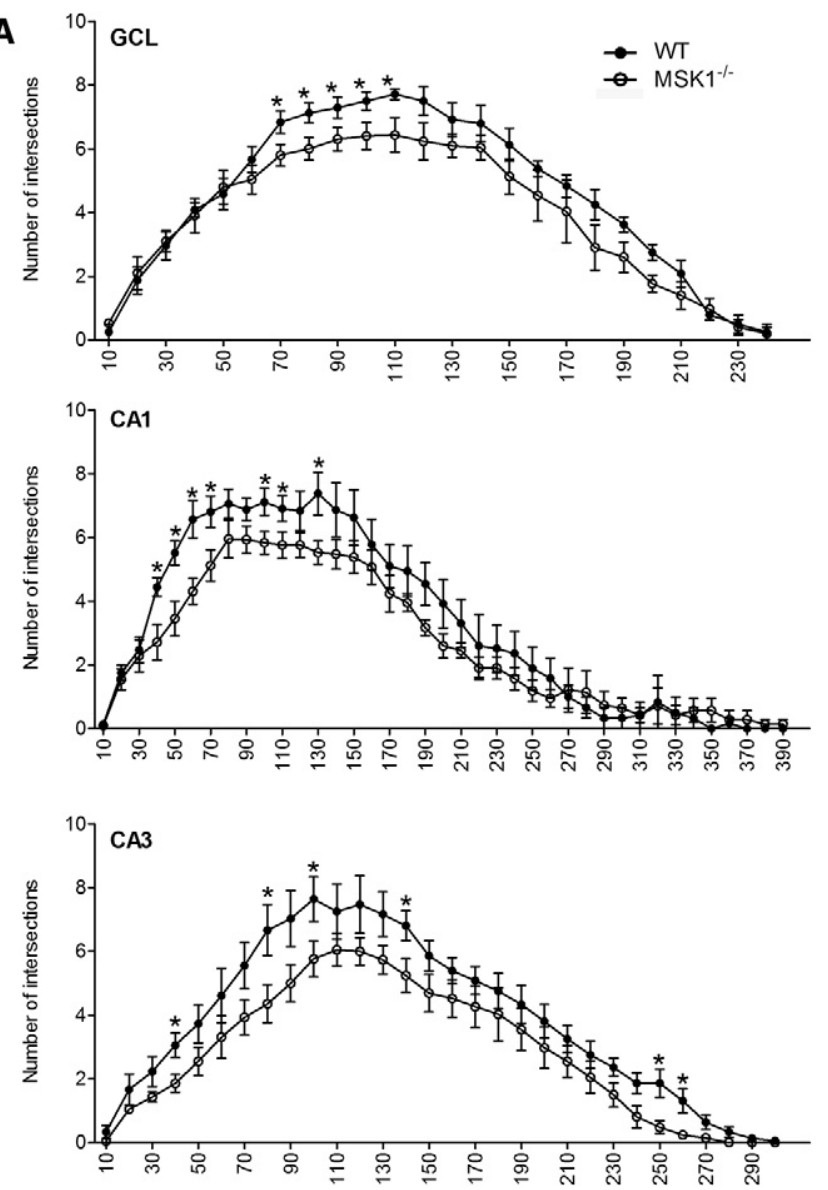

B

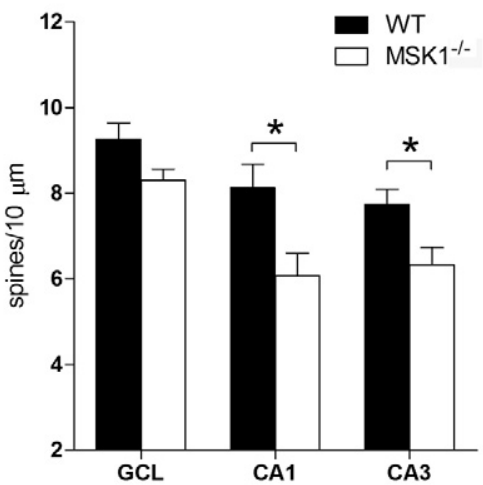

C

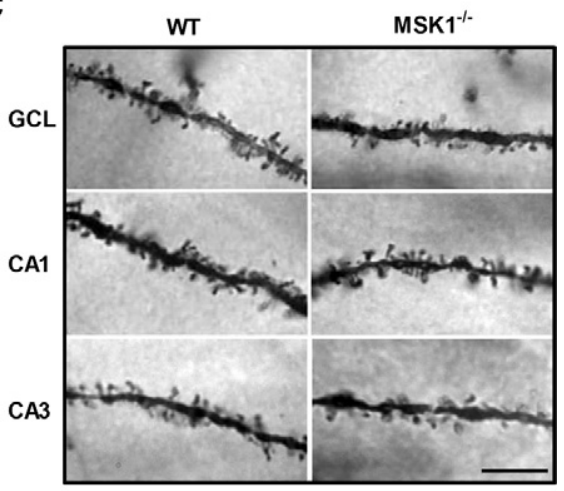

Figure 2. Hippocampal morphology in WT and MSK $1^{-/-}$mice. Sholl analysis of apical dendritic branching complexity in WT and MSK ${ }^{-/-}$mice. For these studies, neuronal morphology was visualized using Golgi-Cox quantification; four to five cells per animal were traced ( $n=6-8 /$ group). ( $A$ ) Compared to WT controls, MSK $1^{-}$mice exhibit reduced dendritic branching complexity in the GCL, CA1, and CA3 regions of the hippocampus. All data are expressed as mean \pm SEM (two-tailed $t$-tests were performed for each Sholl interval), $\left.\left({ }^{*}\right) P<0.05\right)$. (B) Spine density was measured from four to five apical dendrites per animal. Dendritic spine density in the GCL did not differ between WT and MSK1 ${ }^{-/-}$mice but was significantly reduced in $\mathrm{MSK} 1^{-/-}$compared to WT mice in the CA1 $\left(t_{(10)}=2.698, P<0.05\right)$ and CA3 $\left(t_{(11)}=2.638, P<0.05\right)$ regions. $(C)$ Representative highmagnification images revealing dendritic spines, scale bar $=10 \mu \mathrm{m}$.

WT mice, MSK1 deletion resulted in a modest $(\sim 14 \%)$ reduction in DCX-positive cells (Fig. 3C).

\section{Learning/memory}

Changes in hippocampal morphology are closely related to alterations in cognitive function (van Praag et al. 2000). Likewise, the proliferative capacity of the SGZ neurogenic niche is correlated with cognitive capacity (Bruel-Jungerman et al. 2005; Deng et al. 2009). Given that the deletion of MSK1 affected both cell morphology and neurogenesis, we examined the cognitive ramifications of MSK1 deletion. To this end, we initially examined hippocampus-dependent spatial memory of WT and MSK1 $1^{-/-}$ mice using the Barnes maze. Mice were trained over a period of $5 \mathrm{~d}$ to locate and enter an escape hole and were then tested $24 \mathrm{~h}$ later via a probe trial, in which the escape box was removed. All mice learned to locate the escape hole during the course of training, as indicated by a progressive reduction in latency to enter the escape box (Fig. 4A) and reduced error rate (Fig. 4B) over time during the acquisition phase. However, during the first $3 \mathrm{~d}$ of training, $\mathrm{MSK}^{-\gamma-}$ mice exhibited a slower rate of learning as indicated by increased relative latencies to enter the escape box.

Next, we examined recognition memory using the novel object recognition task. In this task, mice were exposed to two iden- tical objects in an open arena for $10 \mathrm{~min}$ and then returned to their home cages for a period of $1 \mathrm{~h}$. Mice were then returned to the same arena with one familiar and one novel object and were assessed for object preference. WT mice spent $\sim 62 \%$ of the time investigating the novel object, indicating that they retained recall memory for the familiar object and thus spent less time investigating it. On the other hand, MSK1 $1^{-/-}$mice did not display a clear object preference and investigated both objects equally (Fig. $4 \mathrm{C})$. In order to establish that the investigation of the individual objects was not affected by differences in locomotion, overall activity was assessed as the number of crossings over the mid-line of the arena during testing. WT and $\mathrm{MSK}^{-/-}$mice did not differ in the number of mid-line crossings, indicating that the reduced novel object preference in $\mathrm{MSK} 1^{-/-}$mice is not attributed to changes in locomotor activity (Fig. 4D).

\section{Learning/memory following environmental enrichment}

Environmental enrichment has been shown to improve cognitive function through enhanced neurogenesis and plasticity (van Praag et al. 2000). Given the reduced degree of hippocampal plasticity in MSK1 $1^{-/-}$mice, we assessed cognitive function in WT and $\mathrm{MSK}^{-/-}$mice following $40 \mathrm{~d}$ of $\mathrm{EE}$, in which mice were housed in "enriched" cages consisting of multiple cage-mates, running 

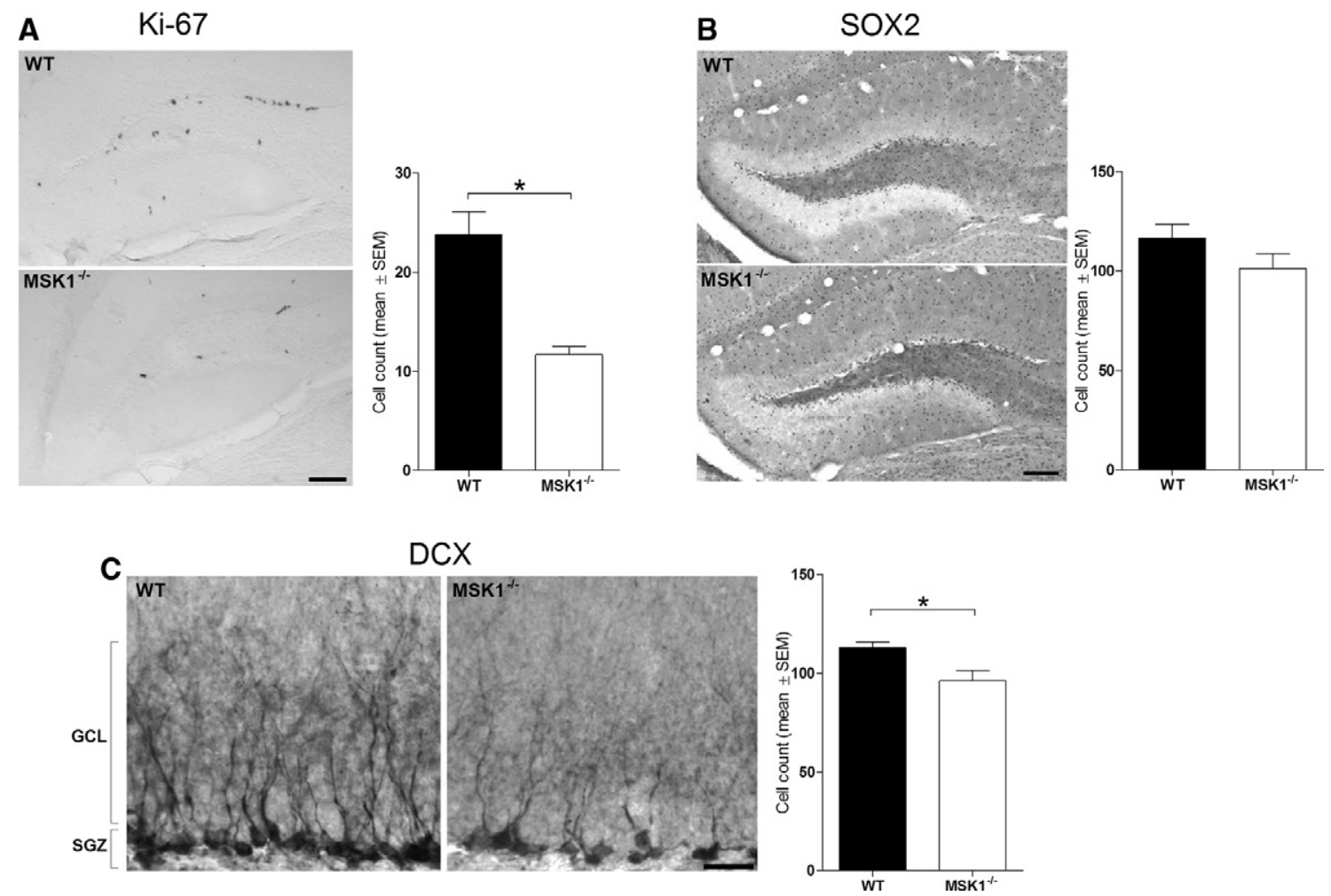

Figure 3. Decreased proliferation in $\mathrm{MSK} 1^{-/-}$mice. $(A)$ Representative immunohistochemical labeling and quantitation of Ki-67 (a marker of proliferating progenitor cells) in the SGZ of WT and MSK1 $1^{-1-}$ mice; the number of Ki-67-positive cells is reduced in MSK1 $1^{-1-}$ mice relative to WT mice $\left(t_{(12)}=5.310, P<0.05\right)$. (B) Representative immunohistochemical labeling and quantitation of SOX2 in the SGZ of WT and MSK1 $1^{-/-}$mice; SOX2 expression is similar between WT and MSK $1^{-/-}$mice. (C) Representative images and quantitation of DCX-positive cells from WT and MSK1 ${ }^{-/-}$mice; MSK1 deletion resulted in a modest reduction in DCX-positive immature neurons in the $G C L\left(t_{(10)}=2.752, P<0.05\right)$. $(A, B) S c a l e$ bar $=100 \mu \mathrm{m}$. (C) $S c a l e$ bar $=$ $50 \mu \mathrm{m}$. Data are expressed as mean \pm SEM $(n=6 /$ group $\left.) .{ }^{*}\right) P<0.05$.

wheels, and plastic toys. Following EE, WT mice exhibited enhanced learning as measured by reduced latency and errors during acquisition compared to MSK1 $1^{-/-}$mice (Fig. 5A,B). Specifically, enriched WT mice exhibited faster learning rates on days $2-4$ of training. A probe trial conducted $24 \mathrm{~h}$ after the final trial revealed increased preference for the target quadrant in WT mice, compared to MSK1 $1^{-/-}$mice (Fig. 5C). Finally, using the novel object preference task, we found an enhanced preference quotient in WT but not MSK1 $1^{-/-}$mice (Fig. 5D).

To provide a more comprehensive overview of the effects of MSK1 deletion and EE, we also provide a composite graphical comparison of Barnes maze and novel object data for WT and MSK1 $^{-/-}$mice under control and EE conditions (Supplemental Fig. S1A). Importantly, compared to control mice, EE enhanced Barnes maze learning in WT mice, particularly on days 2 and 3 of training. In $\mathrm{MSK}^{-/-}$mice, a similar trending effect of EE was detected, although it did not reach statistical significance. Probe testing revealed that enrichment improved memory for the target quadrant in WT mice but not in MSK1 $1^{-/-}$mice (Supplemental Fig. S1C). Similarly, the novel object preference quotient was increased in enriched WT mice (compared to control WT); however, $\mathrm{MSK}^{-/-}$mice did not exhibit improved object recognition following enrichment (Supplemental Fig. S1D).

\section{Experience-induced changes in dendritic morphology}

To establish whether MSK1 regulates experience-dependent neuron plasticity, we assessed the effect of $40 \mathrm{~d}$ of EE on hippocampal morphology in WT and MSK1 null mice. Following enrichment, WT mice exhibited greater GCL and CA1/CA3 dendritic branch- ing compared to MSK1 ${ }^{-/-}$mice (Fig. 6A). Dendritic spine density was also significantly greater in enriched WT mice (Fig. 6B,C).

As with the behavioral analysis, we also provide a composite graphical comparison of neuronal morphology for WT and $\mathrm{MSK}^{-/-}$mice under control and EE conditions (Supplemental Fig. S2). Of note, relative to control, nonenriched mice of the same genotype, EE led to an increase in GCL and CA1/CA3 dendritic branching in both WT and MSK1 null mice (Supplemental Fig. S2A). However, WT mice exhibited a significantly greater increase in dendritic spine density following enrichment than $\mathrm{MSK}^{-/-}$mice (Supplemental Fig. S2B). Further, EE increased GCL and CA1 spine density to the same degree ( $\sim 20 \%$ increase in GCL and 30\% increase in CA1) in both genotypes; however, the total number of spines was significantly greater in WT mice compared to $\mathrm{MSK}^{-/-}$mice in both hippocampal regions. In the CA3 region, only WT mice increased dendritic spine density following EE, whereas $\mathrm{MSK}^{-/-}$mice did not exhibit an EEinduced increase in dendritic spines (Supplemental Fig. S2B,C). These data indicate that the deletion of MSK1 does not eliminate experience-dependent hippocampal plasticity but rather reduces efficacy of EE to induce structural plasticity.

\section{Experience-induced proliferation}

The finding that EE increases the rate of hippocampal neurogenesis, coupled with our work showing that MSK1 regulates the basal rate of progenitor proliferation in the SGZ, raised the prospect that MSK1 may also function as a regulator of inducible progenitor proliferation. Here, we tested whether MSK1 couples EE to an 
A
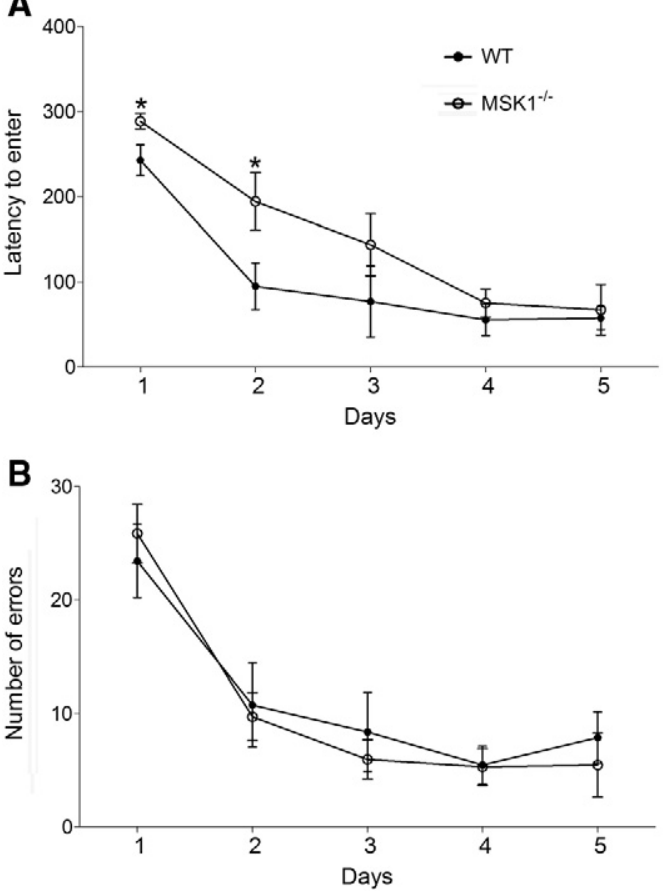

C

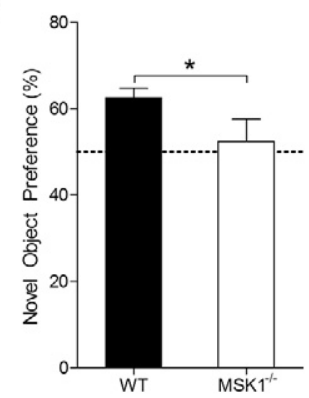

D

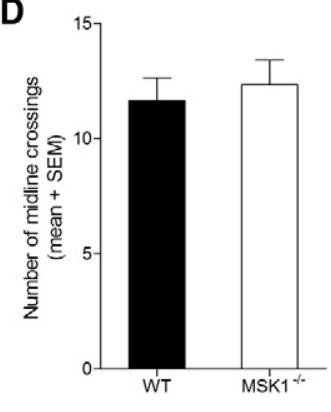

Figure 4. Memory deficits in $\mathrm{MSK} 1^{-/-}$mice. Using the Barnes maze and novel object recognition tests, memory was assessed in WT and MSK $1^{-/-}$mice $(n=6-8 /$ group). During $5 \mathrm{~d}$ of training on the Barnes maze, all mice exhibited learning, as evident by a progressive reduction in $(A)$ latency to enter the escape hole (repeated measures ANOVA, $F_{(4,56)}=29.452, P<0.001$ ) and $(B)$ a reduction in the number of errors (repeated measures ANOVA, $F_{(4,56)}=37.732, P<0.001$ ), measured as investigation of any other holes. Compared to WT mice, MSK1 ${ }^{-}$mice exhibited a relatively slow rate of learning during day $1\left(t_{(14)}=2.249, P<0.05\right)$ and day $2\left(t_{(14)}=2.288, P<0.05\right)$ of training. (C) WT mice displayed a preference for the novel object (shown as percent time spent actively exploring the object); however, $\mathrm{MSK}^{-/-}$mice do not discriminate between the two objects $\left(t_{(14)}=1.793, P=0.05\right)$. $(D)$ Analysis of the number of mid-line crossings during novel object testing indicates that MSK1 deletion did not significantly affect locomotor behavior. Data are expressed as the mean \pm SEM. $\left(^{*}\right) P<0.05$.

increase in the rate of cell proliferation. We utilized the EE method described above as a model for experience-dependent induction of SGZ proliferation. Interestingly, EE significantly enhanced the number of Ki-67-positive progenitor cells in WT mice relative to MSK1 ${ }^{-/-}$mice (Fig. 7A). Of note, a comparison of the Ki-67positive progenitor cells in $\mathrm{MSK} 1^{-/}$mice under control and $\mathrm{EE}$ conditions reveals that inducible progenitor proliferation was completely repressed (Fig. 7A). Together, these data indicate that MSK1 is an important regulator of experience-induced progenitor cell proliferation.

Finally, we assessed CREB phosphorylation at Ser133 (pCREB) following EE. Previous work has detected robust pCREB expression in the SGZ, which has been localized to adult-born immature neuronal cell populations (Merz et al. 2011). Interestingly, WT mice exhibited a much greater level of CREB phosphorylation in the SGZ than MSK1 ${ }^{-/-}$mice (Fig. 7B). Further, in WT mice, EE increased the number of pCREB-positive cells relative to control (nonenriched) conditions. In contrast, the pCREB-positive cell population was not significantly increased following $\mathrm{EE}$ in $\mathrm{MSK1}^{-/-}$mice (Fig. 7B).

\section{Discussion}

\section{Overview of the findings}

CNS neurons exhibit a tremendous range of functional plasticity. Under normal physiological conditions, plasticity can be actuated by brief bouts of synaptic activity, which underlie learning and memory formation, and can also result from ostensibly modest changes in activity that persists over longer periods of time, for example, during EE. Here, the goal was to address the role of MSK1 in both forms of functional plasticity. Our data sets reveal that MSK1 plays a key role in shaping long-term changes in neuronal morphology, processing power, and functional plasticity of the hippocampus.

\section{MSK/MAPK and neuronal morphology}

Dendrites represent a primary source of synaptic contact in the hippocampus. Given this, the data presented here showing that $\mathrm{MSK}^{-/-}$mice exhibit reduced branching complexity of granule and CA1/CA3 neuronal dendrites were of particular interest. Of note, the decrease in CA1 dendrite arborization was most prominent in the proximal-apical region, which receives robust input from Schaffer collaterals (Leranth and Hajszan 2007). In addition, CA1 spine density was also reduced in $\mathrm{MSK}^{-/-}$mice. Excitatory input to CA1 neurons via CA3 Schaffer collateral afferents promotes structural plasticity associated with morphometry of dendrites and spines, and formation of new synapses (Nägerl et al. 2004; Zhang et al. 2008), and thus, a reduction of dendritic arbors in both the proximal-apical CA1 and CA3 regions, coupled with decreased spine density in $\mathrm{MSK} 1^{-/-}$mice, represents an overall change in the neural circuitry that could limit the dynamic range of plasticity within the hippocampus.

Neuronal morphology, as measured by dendrite arborization and spine density, is modulated by a number of extracellular signals (i.e., neurotrophins, neurotransmitters) (Horch and Katz 2002; Zagrebelsky et al. 2005), and signaling via the ERK/MAPK pathway appears to function as a key conduit by which these extracellular cues influence neuronal morphology (Vaillant et al. 2002; Goldin and Segal 2003; Kumar et al. 2005). Interestingly, ERK/ MAPK signaling has been implicated in both transcriptionally dependent and independent forms of structural plasticity (Dijkhuizen and Ghosh 2005). Clearly, given its nuclear localization and its effects on chromatin structure and transcription factor activation, MSK1 would most likely actuate ERK-dependent neuronal morphological plasticity via a transcriptional-dependent mechanism. Here, it is worth noting that, in addition to functioning via the ERK/MAPK cascade, MSK1 is also activated by p38, and signaling via $\mathrm{p} 38$ has been shown to affect (both facilitate and repress) neurite outgrowth (Muroi et al. 2004; Kamata et al. 2007; Kano et al. 2007) and spinogenesis (Sugiura et al. 2009). Clearly, additional studies examining whether the effects of MSK1 on neuronal morphology are driven by ERK/MAPK, p38 or both are merited.

\section{MSK learning and memory}

Recent studies have shown that MSK1 is activated during contextual fear conditioning (Sindreu et al. 2007) and that MSK1 
A

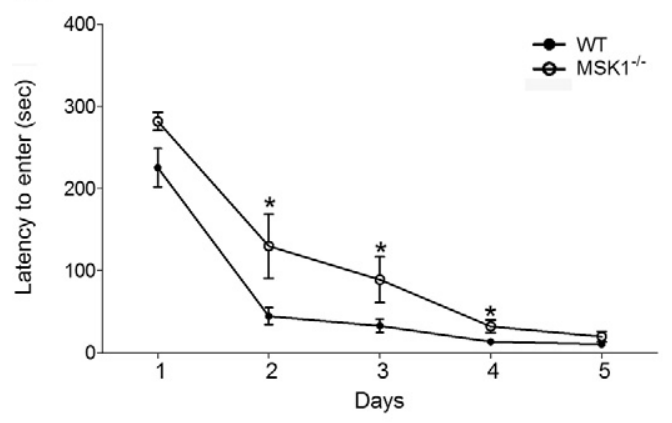

c

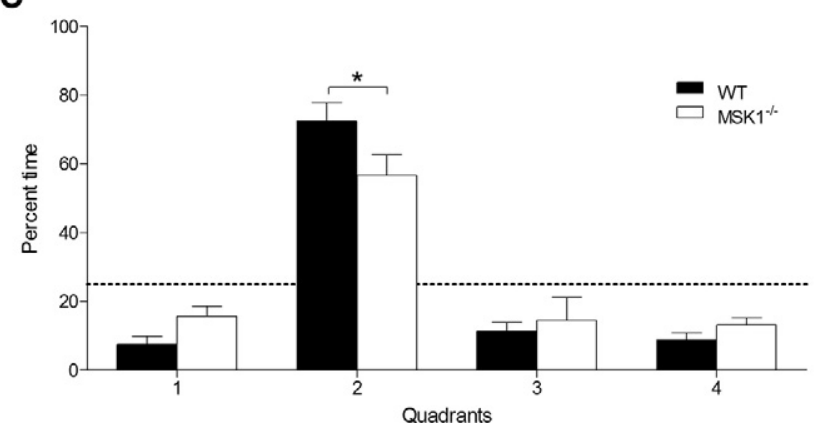

B

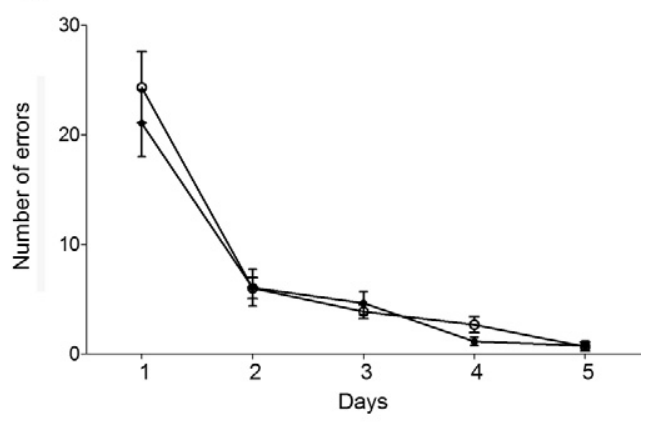

$\mathbf{D}$

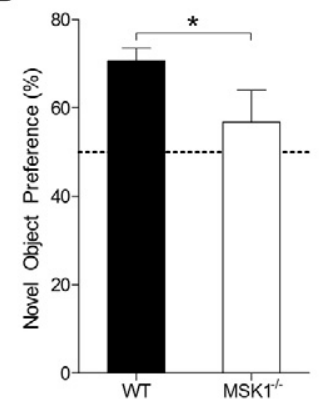

Figure 5. Effect of environmental enrichment on learning and memory in WT and MSK1 ${ }^{-/-}$mice. Barnes maze and novel object recognition assays were performed using WT and MSK $1^{-/-}$mice following $40 \mathrm{~d}$ of $\mathrm{EE}$ ( $n=6-8 /$ group). ( $\left.A, B\right)$. All enriched mice exhibited learning as evidenced by a progressive reduction in the latency to enter the escape hole (repeated measures ANOVA, $\left.F_{(4,20)}=3.060, P<0.05\right)$. Enriched WT mice exhibit a reduced latency to enter the escape hole on day $2\left(t_{(11)}=2.294, P<0.05\right)$, day $3\left(t_{(11)}=2.285, P<0.05\right)$, and day $4\left(t_{(11)}=2.762, P<0.05\right)$ compared to enriched $\mathrm{MSK} 1^{-/-}$mice. Statistically significant group differences $(P<0.05)$ are noted with an asterisk $\left({ }^{*}\right)$. (C) During probe testing (with the escape box removed), all enriched mice showed a preference for the target quadrant. Note that enriched WT mice exhibited increased target quadrant investigation compared to MSK1 ${ }^{-/-}$mice $\left(t_{(13)}=4.607, P<0.001\right)$. $(D)$ Relative to enriched MSK $1^{-/-}$mice, enriched WT mice exhibited enhanced preference for the novel object during the novel object recognition task $\left(t_{(10)}=2.634, P<0.05\right)$.

deletion impairs fear conditioning as well as spatial memory (Chwang et al. 2007). MSK1 ${ }^{-/-}$mice have a deficiency in hippocampal histone $\mathrm{H} 3$ phosphorylation and acetylation (Chwang et al. 2007) and CREB-dependent transcription (Wiggin et al. 2002), three events that are linked to both dendritic plasticity and memory (Hsieh and Gage 2005; Levenson and Sweatt 2005). Consistent with these results, our data indicate that $\mathrm{MSK}^{-/-}$mice display impaired learning for both the Barnes maze and novel object preference tasks.

The two upstream effector cascades of MSK1 (i.e., p38 MAPK and ERK/MAPK) have been shown to play a role in synaptic plasticity, learning, and memory (Alonso et al. 2004; Thomas and Huganir 2004; Sugiura et al. 2009). Along these lines, signaling via the p38 pathway has been shown to regulate a number of plasticity-related processes, including hippocampal LTD, singletrial hippocampal-dependent inhibitory avoidance memory formation, and cerebellar reflex-conditioned responses (Bolshakov et al. 2000; Zhen et al. 2001; Alonso et al. 2004), whereas the disruption of ERK/MAPK signaling impairs spatial memory retention, disrupts fear conditioning (both in the acquisition and extinction phases), and blocks the consolidation of recognition memory (Kelly et al. 2003). Further, MAPK signaling is essential for long-term potentiation, a change in synaptic strength that is believed to be an underlying cellular mechanism for learning and memory (English and Sweatt 1997). Interestingly, both longlasting forms of LTP and LTD drive a wave of robust transcriptional activity (Davis et al. 2000; Fonseca et al. 2004; Lindecke et al. 2006; Yilmaz-Rastoder et al. 2010). Given the recognized roles that MAPK signaling plays in transcriptionally dependent forms of learning and memory, it is reasonable to posit that MSK1 is a key conduit in this process. In line with this thought, studies in MSK $1^{-/-}$mice which focus on the expression of MAPK- and CREB-regulated genes that influence dendrite morphology (e.g., brain-derived neurotrophic factor $[\mathrm{BDNF}]$, miR132, MMP9) could provide important clues regarding the mechanism by which MSK1 regulates LTP, neuronal morphology, and, relatedly, cognition.

Here, it is worth briefly noting that the MKS1 phenotypic behavioral effects described here are likely to involve a number of brain regions in addition to the hippocampus. Along these lines, while hippocampal lesions have been shown to significantly impair object recognition (Broadbent et al. 2010), cortical regions such as the perirhinal and medial prefrontal cortex are also implicated in object recognition (Barker and Warburton 2011), as is the basolateral amygdala (Roozendaal et al. 2008). Hence, the involvement of MSK1 in these brain regions cannot be excluded as a contributing factor to the observed object recognition memory deficits.

\section{MSK1 and progenitor proliferation and neurogenesis}

The expression of MSK1 in progenitor cells as well as DCX-positive cells in the SGZ led us to examine whether proliferation was altered in $\mathrm{MSK}^{-/-}$mice. Here, we observed that MSK1 ${ }^{-/-}$mice exhibit a reduction in progenitor cell proliferation and hippocampal neurogenesis. As noted, the total number of SOX2-positive cells within the SGZ was not altered by MSK1 deletion, thus suggesting that the pool of mitotically active progenitors was not altered but 

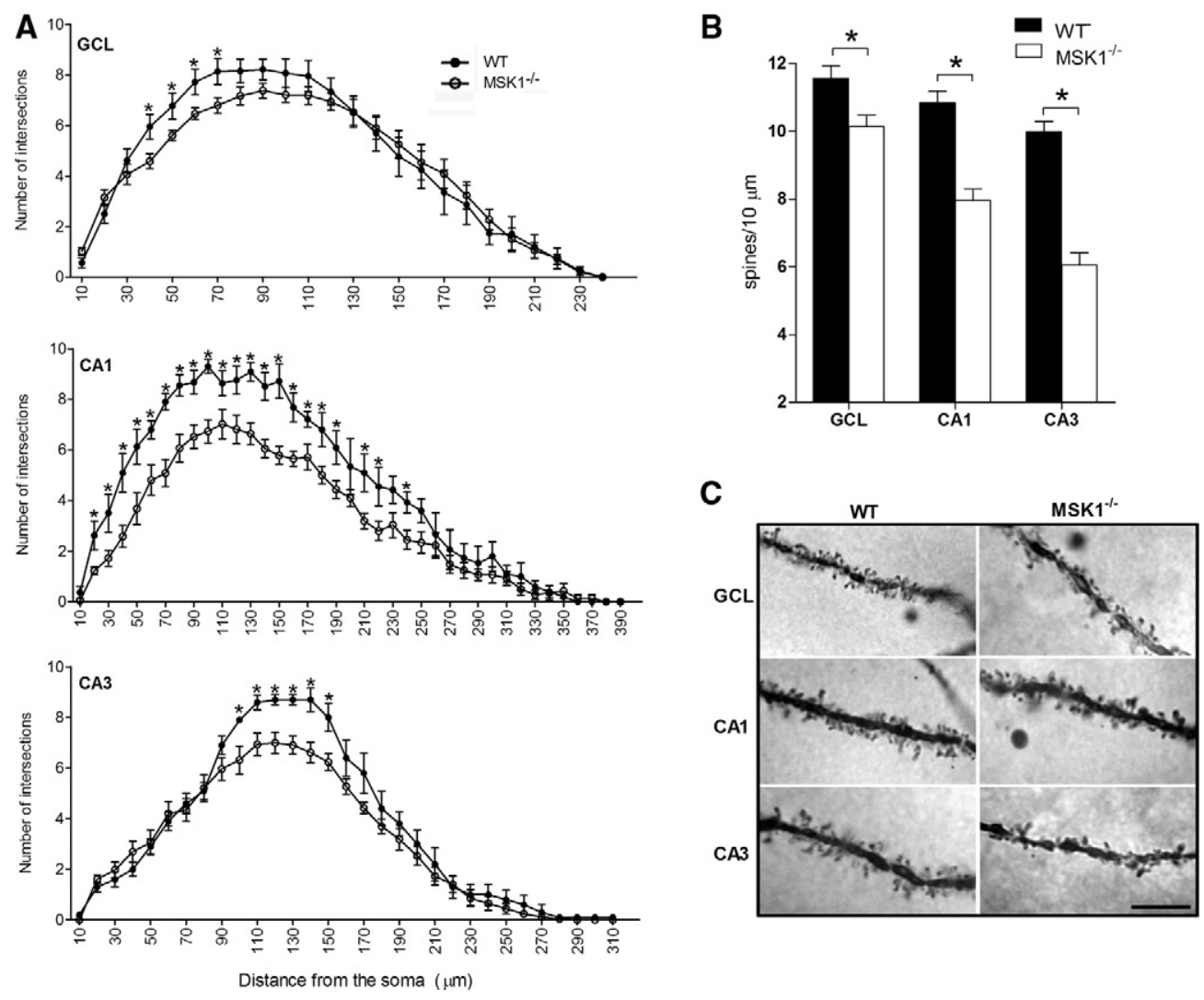

Figure 6. Experience-induced hippocampal morphology in WT and $M S K 1^{-/-}$mice. (A) Following enrichment, WT mice exhibit increased dendritic
branching complexity in the $G C L$ and $C A 1 / C A 3$ regions of the hippocampus as compared to MSK1 $1^{-/-}$mice (four to five cells per animal were branching complexity in the $\mathrm{GCL}$ and CA1/CA3 regions of the hippocampus as compared to MSK1 1 mice (four to five cells per animal were
traced $[n=6-8 /$ group]). One-way ANOVA tests were performed for each Sholl interval, followed by Tukey post-hoc analysis. Statistically significant group differences $(P<0.05)$ are noted with an asterisk $\left(^{*}\right)$. $(B)$ Dendritic spine density is increased in enriched WT mice compared to enriched MSK1 ${ }^{-1-}$ mice in all three hippocampal regions; $G C L\left(t_{(11)}=2.872, P<0.05\right), C A 1\left(t_{(11)}=5.781, P<0.001\right)$, and $C A 3\left(t_{(10)}=8.216, P<0.001\right)$. (C) High-magnification representative EE dendritic spines, scale bar $=10 \mu \mathrm{m}$.

rather that the proliferative capacity of the resident progenitor pool was affected. As expected, the reduction in mitotically active progenitors corresponded with a reduction in the number of immature, adult-born neurons. The reduction in proliferation could have a profound effect on hippocampus-dependent cognitive capacity. Of note, adult-born neurons play an important role in replenishing the pool of granule cells within the dentate gyrus, and a reduction in the generation of adult-born neurons has been shown to affect an array of cognitive processes, including long-term recognition memory, long-term spatial memory, and eye blink trace conditioning (Shors et al. 2001; Bruel-Jungerman et al. 2005; Deng et al. 2009). Interestingly a number of studies have shown that the MAPK pathway plays an important role in mitotic activity of progenitor cells in the developing CNS as well as in the neurogenic niche of the adult SGZ (Alonso et al. 2004; Choi et al. 2008). Some of the effects of MAPK signaling on proliferation have been ascribed to the effector kinase RSK (Zhang and Liu 2002; Hauge and Frodin 2006), whereas the role of other kinase pathways has not been well established. Clearly, the work presented here provides an interesting context within which to examine the precise mechanism by which MSK1 affects progenitor proliferation as well as neurogenesis.

\section{Environmental enrichment}

A number of studies have shown that the cognitive gains resulting from EE correspond to an increase in dendritic complexity and an increased rate of neurogenesis in the hippocampus (Kempermann et al. 1998; Nilsson et al. 1999; Faherty et al. 2003). Given our data showing that MSK1 regulates dendrite morphology and progenitor proliferation, we posited that MSK1 may play a role in coupling EE to enhanced cognitive capacity. Indeed, our data revealed that $\mathrm{MSK}^{-/-}$mice exhibited a compromised capacity to couple EE to cognitive enhancement. Hence, in Barnes maze testing of hippocampus-dependent spatial memory, the cognitive enhancement resulting from $40 \mathrm{~d}$ of EE in WT mice was markedly attenuated in $\mathrm{MSK}^{-/-}$mice. Particularly noteworthy was the distinct difference in the rate of memory consolidation after $2 \mathrm{~d}$ of Barnes maze training, where enriched WT mice rapidly learned to orient to and access the escape box. In contrast, enriched $\mathrm{MSK}^{-1-}$ mice took over twice as long to perform the same task at this time point. Of note, however, Barnes data revealed that enriched MSK1 ${ }^{-/-}$mice exhibited improved performance relative to nonenriched $\mathrm{MSK}^{-/-}$animals. Together, these data reveal that MSK1 significantly contributes to but is not the exclusive route by which EE drives cognitive enhancement. Other activity-inducible kinase pathways, such as PKA, PKC, and other MAPK-regulated signaling pathways, are also likely to contribute to EE-evoked cognitive enhancement.

Following the acquisition trials, which reflect the speed with which animals learn the task, a probe trial was used as an indicator that spatial memory has been formed (Jeltsch et al. 2001; Kempermann and Gage 2002). As expected, enriched WT mice spent significantly more time in the target quadrant than 

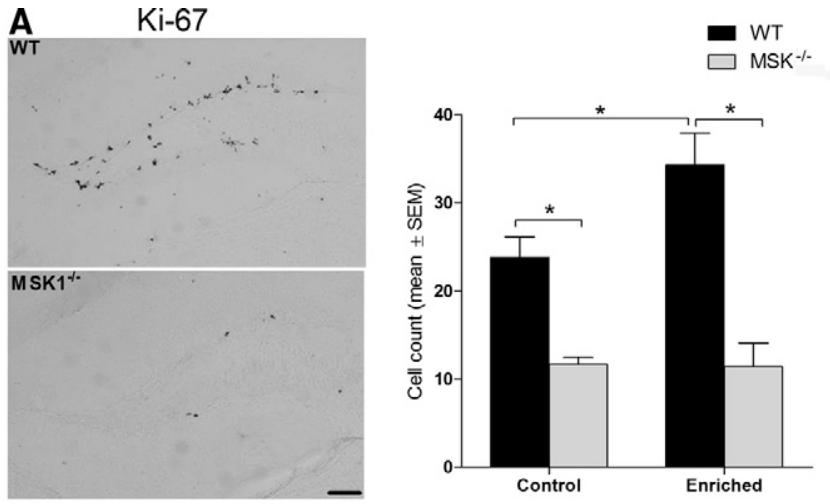

B

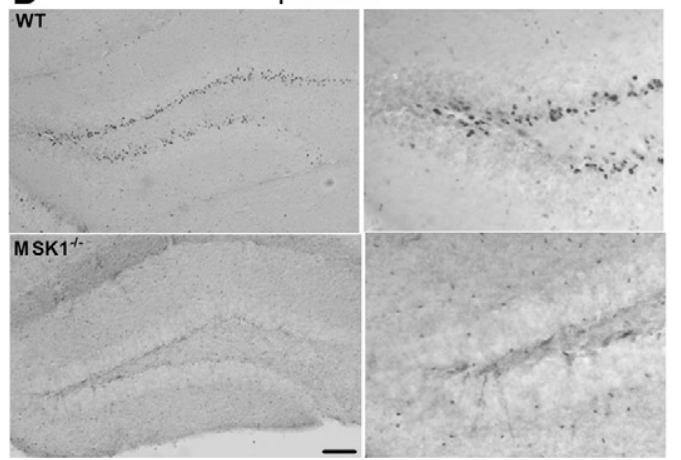

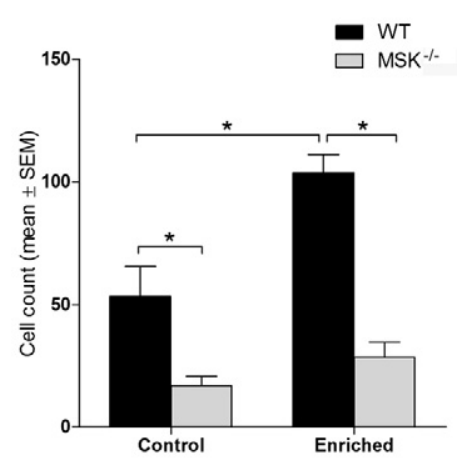

Figure 7. Experience-induced proliferation. Note that in order to directly illustrate the impact of EE on progenitor cell proliferation, $\mathrm{Ki}-67$ immunohistochemistry data from enriched mice are graphed along with control/nonenriched mice, as shown in Figure 3. WT and $\mathrm{MSK}^{-1-}$ mice were killed following 40 $\mathrm{d}$ of $\mathrm{EE}$ ( $n=6-8 /$ group). (A) Representative immunohistochemical labeling and quantitation of Ki-67 in the SGZ of enriched WT and MSK1 ${ }^{-/-}$mice. Enrichment increases the number of Ki-67-positive cells relative to control/nonenriched conditions in WT mice $\left(t_{(9)}=3.068, P<0.05\right)$, whereas in MSK $1^{-/-}$ mice, the number of Ki-67-positive cells was not increased following enrichment. (B) Representative immunohistochemical labeling and quantitation of pCREB in the SGZ of enriched WT and MSK1 ${ }^{-1-}$ mice. Enrichment increased the number of pCREB-positive cells relative to the control/nonenriched condition in WT mice (immunohistochemical labeling for control conditions not shown; $t_{(9)}=2.449, P<0.05$ ). In MSK1 ${ }^{-/-}$mice, the number of pCREB-positive cells was not significantly increased following enrichment. Scale bar $=100 \mu \mathrm{m} .\left(^{*}\right) P<0.05$.

nonenriched WT mice; in contrast, enriched and control $\mathrm{MSK}^{-/-}$mice spent approximately the same amount of time in the target quadrant. Thus, in $\mathrm{MSK}^{-/-}$mice, although enrichment led to a slight cognitive enhancement during the acquisition phase of the Barnes maze trial, spatial memory retention was not enhanced during the probe trial. A similar distinction was detected using the novel object recognition test, in which EE did not result in cognitive enhancement in $\mathrm{MSK}^{-/-}$mice. Together, these findings indicate a role for MSK1 as a mediator of spatial and recall memory.

In $\mathrm{MSK}^{-/-}$mice, the attenuated capacity for EE-evoked cognitive enhancement was paralleled by a blunted morphogenic and cell proliferation phenotype. Exposure to EE is believed to promote dendritic arborization and spine growth through increasing concentrations of neurotrophins, such as brain-derived neurotrophic factor, nerve growth factor, and neurotrophin-3 (Ickes et al. 2000). Interestingly, ERK/MAPK signaling plays a key role in the inducible expression of neurotrophins and also serves as a downstream kinase effector of neurotrophin receptor activation (Finkbeiner et al. 1997; Kaplan and Miller 2000). For example, the expression of BDNF is mediated by an ERK/MAPK/CREB signaling cassette (Shieh and Ghosh 1999; Su et al. 2011), and signaling via $\mathrm{BDNF} / \mathrm{TrkB}$ affects cellular morphology via actuation of

\section{Barnes maze}

ERK/MAPK/CREB (Alonso et al. 2004). Given these findings, one could envision MSK1 functioning within a positivefeedback circuit by which EE drives both neurotrophin expression and, in turn, neurotrophin-dependent enhancement of morphological plasticity.

\section{Conclusions}

In conclusion, the data sets presented here indicate that MSK1 forms a central building block upon which CNS functional plasticity is constructed. Further work examining the precise mechanism by which MSK1 affects dendrite architecture and progenitor proliferation should provide important insights into the cellular processes by which cognition is shaped by experience. In turn, these insights could ultimately help guide the development of therapeutic strategies designed to alleviate an array of acquired and congenital cognitive disorders.

\section{Materials and Methods}

\section{Animals}

$\mathrm{MSK}^{-/-}$mice were kindly provided by Dr. J. Simon Arthur (University of Dundee, Dundee, Scotland) and bred at Ohio State University. MSK1 $1^{-/-}$mice were generated by crossing heterozygous mice. The MSK targeted strains were backcrossed into the C57/bl6 line over eight generations. Mice were genotyped using the primer sets and cycling conditions described by Wiggin et al. (2002). Adult (8- to 10-wk-old) MSK1 - / - and wild type mice were maintained on a 12:12 light/dark cycle in a temperatureand humidity-controlled vivarium. All mice were allowed ad libitum access to food and water. The study was conducted in accordance with Ohio State University guidelines for the care and use of animals and under protocols approved by the Institutional Animal Care and Use Committee.

\section{Enrichment paradigm}

Enriched housing conditions were adapted from van Praag et al. (2000) and consisted of a large rat cage $(44.7 \times 23.5 \times 15.2 \mathrm{~cm})$, plastic tubes, toys, a running wheel, and nesting material. Standard housing conditions consisted of a standard mouse cage $(31.8 \times 17.1 \times 14 \mathrm{~cm})$ and nesting material. Mice were divided into four groups: (1) control wild type (standard cage), (2) enriched wild type (enriched cage), (3) control MSK1 ${ }^{-}{ }_{-}^{-}$, and (4) enriched MSK1 ${ }^{-/}$. . All mice were maintained in assigned housing conditions for $40 \mathrm{~d}$ before testing and tissue collection.

\section{Behavioral analysis}

The Barnes maze test of learning and memory was adapted from Sunyer et al. (2007). The maze consists of a circular platform (92-cm diameter) elevated $76 \mathrm{~cm}$ above the floor with 20 equally spaced holes. A black acrylic escape box was placed under one of the holes. Visual cues (geometric shapes) were placed on walls surrounding the maze. A bright light (120W, in addition to overhead 
lighting) and an electronic metronome (Boss DB-66, $440 \mathrm{~Hz}$, $85 \mathrm{~dB}$ ) provided the aversive stimuli. A video camera mounted above the maze was used to monitor performance. Testing consisted of five acquisition days followed by a single probe trial $24 \mathrm{~h}$ after the last training trial. Each acquisition day consisted of three 5-min trials with a 10-min inter-trial interval. A trial ended when the mouse entered the escape box. If a mouse did not enter the escape box by the end of the trial, it was gently guided to it and assigned a latency of $300 \mathrm{sec}$. The probe consisted of a single 90 -sec trial with the escape box removed. The surface of the maze and escape box were thoroughly cleaned with $70 \%$ ethanol after every trial to eliminate olfactory cues.

\section{Novel object recognition}

The novel object recognition test was performed as previously described (Hansen et al. 2010). Briefly, mice were exposed to two identical objects for $10 \mathrm{~min}$ and returned to home cages. One hour after the initial exposure, mice were exposed to the same testing arena in which one of the familiar objects was replaced with a novel object. During a 5-min trial, the time (in sec) spent actively investigating each object was recorded, and a novel object preference quotient was determined \{[novel/ (novel + familiar) $] \times 100\}$. The testing arena and objects were thoroughly cleaned with $70 \%$ ethanol after every trial.

\section{Tissue processing and immunohistochemistry}

Brain tissue was removed following behavioral analysis, and the right and left hemispheres were immediately separated in order to process one hemisphere for immunolabeling analysis and the other for Golgi-Cox morphology analysis.

For immunohistochemistry, one hemisphere was post-fixed in $4 \%$ paraformaldehyde for $6 \mathrm{~h}$ and cryoprotected with $30 \%$ sucrose in PBS. Brain sections were then thin-cut $(40 \mu \mathrm{m})$ on a freezing microtome. Adjacent sections were washed and incubated in $0.3 \%$ hydrogen peroxide in $20 \%$ methanol for $20 \mathrm{~min}$. Following PBS washing, sections were blocked with 10\% normal goat serum followed by overnight incubation at $4^{\circ} \mathrm{C}$ with the following antibodies: rabbit anti-MSK1 (1:1000, Cell Signaling), rabbit anti-pCREB (1:1000, Cell Signaling), or rabbit anti-Ki67 (1:2000, Vector Labs). Sections were processed using the ABC staining method (Vector Labs) and visualized with nickelintensified DAB (Vector Labs).

For immunofluorescence, sections were washed with PBS and blocked with $10 \%$ normal horse serum followed by overnight incubation at $4^{\circ} \mathrm{C}$ with the following antibodies: rabbit anti-MSK1 (1:2000), goat anti-doublecortin (DCX: 1:500, Santa Cruz Biotechnology), or goat anti-SOX2 (1:500, Santa Cruz Biotechnology). Following PBS washes, sections were then incubated with AlexaFluor secondary antibodies conjugated with Alexa 488 or Alexa 594 (1:500, Invitrogen). Fluorescence images were captured using a Zeiss 510 confocal microscope.

\section{Cresyl violet staining}

A separate cohort of $\mathrm{WT}$ and $\mathrm{MSK} 1^{-/-}$mice were transcardially perfused and their brain tissue processed for cresyl violet staining. Sections were mounted on gelatin-coated slides, dehydrated in graded alcohol solutions, and incubated in $0.3 \%$ cresyl violet solution. Sections were then destained with $0.1 \%$ glacial acetic acid in 95\% ethanol, cleared in xylene, and mounted with Permount. Every fifth $40-\mu \mathrm{m}$ section was mounted and stained for hippocampal volume quantitation.

\section{Cell quantitation}

To quantitate Ki-67, SOX2, DCX, and pCREB expression in the SGZ, cells were counted unilaterally in three dorsal hippocampal sections. Cell counts are reported as the average of three counts per animal. Hippocampal volume was estimated from $10 \times$ magnification photomicrographs of cresyl violet-stained sections (Paxinos and Watson [2007] coordinates: Bregma $-1.22 \mathrm{~mm}$ to $-2.70 \mathrm{~mm}$ ) using the Cavalieri method (Cruz-Orive 1999).
Using ImageJ software (Rasband 1997-2012), a grid was superimposed onto each image. Briefly, the hippocampal area was manually outlined in seven slices per animal, the total number of pixels was converted into $\mu \mathrm{m}^{2}$, then multiplied by the distance between sections to obtain hippocampal volume (in $\mathrm{mm}^{3}$ ). Left and right hippocampal volumes were calculated separately, then summed together. All quantitation analyses were performed by an experimenter blinded to genotype and housing conditions.

\section{Golgi labeling and analysis}

The remaining brain hemisphere was processed for Golgi analysis using the FD Rapid GolgiStain Kit (FD NeuroTechnologies) according to the manufacturer's protocol. Apical dendrites of GCL and pyramidal neurons in the CA1/CA3 regions of the hippocampus were selected for Sholl and spine density analysis. Pyramidal neurons were identified by their characteristic triangular shaped soma and apical dendrites extending toward the pial surface. Neurons were selected for analysis when all dendritic arbors were found intact and unobstructed by overlapping dendrites of neighboring cells. Sections were visualized using a Nikon E800 brightfield microscope, and 4-5 neurons per animal that met the selection criteria were traced $(20 \times$ magnification) using Neurolucida software (MicroBrightField). The morphology of the reconstructed cells was quantified using NeuroExplorer. Sholl analysis was performed by counting the number of intersections of dendrites on concentric Sholl rings (10- $\mu \mathrm{m}$ intervals). Total dendritic length and cell body area were also calculated. For spine density analysis, high-magnification $(1000 \times)$ images of secondary apical dendrites were captured. Spines were counted across a $20-\mu \mathrm{m}$ section beginning $\sim 100 \mu \mathrm{m}$ from the cell body. All analyses were performed by an experimenter blinded to genotyping and housing conditions.

\section{Western blot}

Isolated hippocampal tissue was processed using Western blotting as previously described. Briefly, hippocampi were lysed in radioimmunoprecipitation assay buffer and protein extracts $(5 \mu \mathrm{g} / \mu \mathrm{L})$, electrophoresed into a 10\% SDS-PAGE gel, transblotted onto polyvinylidene difluoride membranes (Immobilon-P; Millipore) and blocked in 5\% milk in Tris-buffered saline with $0.1 \%$ triton (TBS-T). The membranes were then incubated overnight at $4^{\circ} \mathrm{C}$ in TBS-T with goat anti-MSK1 antibody (1:1000, Santa Cruz), followed by anti-goat IgG horseradish peroxidase-conjugated antibody (1:2000, PerkinElmer Life Sciences).

\section{Statistical analysis}

Immunohistochemistry and morphology data comparisons were made using a Student's $t$-test. Behavioral analysis data were compared using a repeated measures ANOVA (for latency and error Barnes Maze data) or one-way ANOVA followed by a post-hoc Tukey analysis. Data were considered significant for $P$-values $<0.05$.

\section{Acknowledgments}

This work was supported by The American Heart Association Postdoctoral Fellowship number 11POST7410015 and the National Institutes of Health Grant numbers NS066345, NS06740, and MH062335.

\section{References}

Agrigoroaei S, Lachman ME. 2011. Cognitive functioning in midlife and old age: Combined effects of psychosocial and behavioral factors. $J$ Gerontol B Psychol Sci Soc Sci 66: i130-i140.

Alonso M, Medina JH, Pozzo-Miller L. 2004. ERK1/2 activation is necessary for BDNF to increase dendritic spine density in hippocampal CA1 pyramidal neurons. Learn Mem 11: 172-178.

Arthur JSC, Cohen P. 2000. MSK1 is required for CREB phosphorylation in response to mitogens in mouse embryonic stem cells. FEBS Lett 482: $44-48$. 
Arthur JSC, Fong AL, Dwyer JM, Davare M, Reese E, Obrietan K, Impey S. 2004. Mitogen- and stress-activated protein kinase 1 mediates cAMP response element-binding protein phosphorylation and activation by neurotrophins. J Neurosci 24: 4324-4332.

Barker GRI, Warburton EC. 2011. When is the hippocampus involved in recognition memory? J Neurosci 31: 10721-10731.

Bianchi M, Fone K, Azmi N, Heidbreder C, Hagan J, Marsden C. 2006. Isolation rearing induces recognition memory deficits accompanied by cytoskeletal alterations in rat hippocampus. Eur J Neurosci 24: 2894-2902.

Bolshakov V, Carboni L, Cobb M, Siegelbaum S, Belardetti F. 2000. Dual MAP kinase pathways mediate opposing forms of long-term plasticity at CA3-CA1 synapses. Nat Neurosci 3: 1107-1112.

Broadbent NJ, Gaskin S, Squire LR, Clark RE. 2010. Object recognition memory and the rodent hippocampus. Learn Mem 17: 5-11.

Bruel-Jungerman E, Laroche S, Rampon C. 2005. New neurons in the dentate gyrus are involved in the expression of enhanced long-term memory following environmental enrichment. Eur J Neurosci 21: $513-521$.

Choi YS, Cho HY, Hoyt KR, Naegele JR, Obrietan K. 2008. IGF-1 receptor-mediated ERK/MAPK signaling couples status epilepticus to progenitor cell proliferation in the subgranular layer of the dentate gyrus. Glia 56: 791-800.

Chwang WB, Arthur JS, Schumacher A, Sweatt JD. 2007. The nuclear kinase mitogen- and stress-activated protein kinase 1 regulates hippocampal chromatin remodeling in memory formation. J Neurosci 27: $12732-12742$

Cotman CW, Berchtold NC. 2002. Exercise: A behavioral intervention to enhance brain health and plasticity. Trends Neurosci 25: 295-301.

Cruz-Orive LM. 1999. Precision of Cavalieri sections and slices with local errors. J Microsc 193: 182-198.

Davis S, Vanhoutte P, Pagès C, Caboche J, Laroche S. 2000. The MAPK/ERK cascade targets both Elk-1 and cAMP response element-binding protein to control long-term potentiation-dependent gene expression in the dentate gyrus in vivo. J Neurosci 20: 4563-4572.

Deak M, Clifton AD, Lucocq JM, Alessi DR. 1998. Mitogen- and stress-activated protein kinase-1 (MSK1) is directly activated by MAPK and SAPK2/p38, and may mediate activation of CREB. EMBO J 17: $4426-4441$.

Deng W, Saxe MD, Gallina IS, Gage FH. 2009. Adult-born hippocampal dentate granule cells undergoing maturation modulate learning and memory in the brain. J Neurosci 29: 13532-13542.

Dijkhuizen PA, Ghosh A. 2005. BDNF regulates primary dendrite formation in cortical neurons via the PI3-kinase and MAP kinase signaling pathways. J Neurobiol 62: 278-288.

English JD, Sweatt JD. 1997. A requirement for the mitogen-activated protein kinase cascade in hippocampal long term potentiation. J Biol Chem 272: 19103-19106.

Erickson KI, Voss MW, Prakash RS, Basak C, Szabo A, Chaddock L, Kim JS, Heo S, Alves H, White SM. 2011. Exercise training increases size of hippocampus and improves memory. Proc Natl Acad Sci 108: 3017-3022.

Faherty CJ, Kerley D, Smeyne RJ. 2003. A Golgi-Cox morphological analysis of neuronal changes induced by environmental enrichment. Dev Brain Res 141: $55-61$.

Finkbeiner S, Tavazoie SF, Maloratsky A, Jacobs KM, Harris KM, Greenberg ME. 1997. CREB: A major mediator of neuronal neurotrophin responses. Neuron 19: 1031-1047.

Fonseca R, Nägerl UV, Morris RGM, Bonhoeffer T. 2004. Competing for memory: Hippocampal LTP under regimes of reduced protein synthesis. Neuron 44: 1011-1020.

Goldin M, Segal M. 2003. Protein kinase C and ERK involvement in dendritic spine plasticity in cultured rodent hippocampal neurons. Eur J Neurosci 17: 2529-2539.

Hansen KF, Sakamoto K, Wayman GA, Impey S, Obrietan K. 2010 Transgenic miR132 alters neuronal spine density and impairs novel object recognition memory. PLoS One 5: e15497. doi: 10.1371/ journal.pone.0015497.

Hauge C, Frodin M. 2006. RSK and MSK in MAP kinase signaling. J Cell Sci 119: $3021-3023$

Horch HW, Katz LC. 2002. BDNF release from single cells elicits local dendritic growth in nearby neurons. Nat Neurosci 5: 1177-1184.

Hsieh J, Gage FH. 2005. Chromatin remodeling in neural development and plasticity. Curr Opin Cell Biol 17: 664-671.

Ibi D, Takuma K, Koike H, Mizoguchi H, Tsuritani K, Kuwahara Y, Kamei H, Nagai T, Yoneda Y, Nabeshima T. 2008. Social isolation rearing-induced impairment of the hippocampal neurogenesis is associated with deficits in spatial memory and emotion-related behaviors in juvenile mice. J Neurochem 105: 921-932.

Ickes BR, Pham TM, Sanders LA, Albeck DS, Mohammed AH, Granholm AC. 2000. Long-term environmental enrichment leads to regional increases in neurotrophin levels in rat brain. Exp Neurol 164: 45-52.
Jeltsch H, Bertrand F, Lazarus C, Cassel JC. 2001. Cognitive performances and locomotor activity following dentate granule cell damage in rats: Role of lesion extent and type of memory tested. Neurobiol Learn Mem 76: 81-105.

Kamata Y, Shiraga H, Tai A, Kawamoto Y, Gohda E. 2007. Induction of neurite outgrowth in PC12 cells by the medium-chain fatty acid octanoic acid. Neuroscience 146: 1073-1081.

Kano Y, Nohno T, Shimada K, Nakagiri S, Hiragami F, Kawamura K, Motoda H, Numata K, Murai H, Koike Y. 2007. Osmotic shock-induced neurite extension via activation of $\mathrm{p} 38$ mitogen-activated protein kinase and CREB. Brain Res 1154: $1-7$.

Kaplan DR, Miller FD. 2000. Neurotrophin signal transduction in the nervous system. Curr Opin Neurobiol 10: 381-391.

Kelly Á, Laroche S, Davis S. 2003. Activation of mitogen-activated protein kinase/extracellular signal-regulated kinase in hippocampal circuitry is required for consolidation and reconsolidation of recognition memory. J Neurosci 23: 5354-5360.

Kempermann G, Gage F. 2002. Genetic determinants of adult hippocampal neurogenesis correlate with acquisition, but not probe trial performance, in the water maze task. Eur J Neurosci 16: 129-136.

Kempermann G, Kuhn HG, Gage FH. 1997. More hippocampal neurons in adult mice living in an enriched environment. Nature 386: 493-495.

Kempermann G, Brandon EP, Gage FH. 1998. Environmental stimulation of $129 / \mathrm{SvJ}$ mice causes increased cell proliferation and neurogenesis in the adult dentate gyrus. Curr Biol 8: 939-944.

Komitova M, Eriksson PS. 2004. Sox-2 is expressed by neural progenitors and astroglia in the adult rat brain. Neurosci Lett 369: 24-27.

Kumar V, Zhang MX, Swank MW, Kunz J, Wu GY. 2005. Regulation of dendritic morphogenesis by Ras-PI3K-Akt-mTOR and Ras-MAPK signaling pathways. J Neurosci 25: 11288-11299.

Leranth C, Hajszan T. 2007. Extrinsic afferent systems to the dentate gyrus. Prog Brain Res 163: 63-799.

Levenson JM, Sweatt JD. 2005. Epigenetic mechanisms in memory formation. Nat Rev Neurosci 6: $108-118$

Lindecke A, Korte M, Zagrebelsky M, Horejschi V, Elvers M, Widera D, Prüllage M, Pfeiffer J, Kaltschmidt B, Kaltschmidt C. 2006. Long-term depression activates transcription of immediate early transcription factor genes: Involvement of serum response factor/Elk-1. Eur J Neurosci 24: $555-563$.

Martin E, Betuing S, Pagès C, Cambon K, Auregan G, Deglon N, Roze E, Caboche J. 2011. Mitogen- and stress-activated protein kinase 1 -induced neuroprotection in Huntington's disease: Role on chromatin remodeling at the PGC-1-alpha promoter. Hum Mol Genet 20: $2422-2434$.

Merz K, Herold S, Lie DC. 2011. CREB in adult neurogenesis-master and partner in the development of adult born neurons? Eur J Neuro 33: $1078-1086$.

Muroi Y, Ishii T, Teramoto K, Hori M, Nishimura M. 2004. Calcineurin contributes to the enhancing effect of adenosine on nerve growth factor-induced neurite outgrowth via the decreased duration of $\mathrm{p} 38$ mitogen-activated protein kinase phosphorylation. J Pharmacol Sci 95: $124-131$

Nägerl UV, Eberhorn N, Cambridge SB, Bonhoeffer T. 2004. Bidirectional activity-dependent morphological plasticity in hippocampal neurons. Neuron 44: 759-767.

Nilsson M, Perfilieva E, Johansson U, Orwar O, Eriksson PS. 1999. Enriched environment increases neurogenesis in the adult rat dentate gyrus and improves spatial memory. J Neurobiol 39: 569-578.

Paxinos G, Watson C. 2007. The rat brain in stereotaxic coordinates: Hard cover edition. Academic Press, Waltham, MA.

Rasband WS. 1997-2012. ImageJ. U.S. National Institutes of Health, Bethesda, MD. http://imagej.nih.gov/ij/.

Roozendaal B, Castello NA, Vedana G, Barsegyan A, McGaugh JL. 2008. Noradrenergic activation of the basolateral amygdala modulates consolidation of object recognition memory. Neurobiol Learn Mem 90: $576-579$.

Scholzen T, Gerdes J. 2000. The Ki-67 protein: From the known and the unknown. J Cell Physiol 182: 311-322.

Shieh PB, Ghosh A. 1999. Molecular mechanisms underlying activitydependent regulation of BDNF expression. J Neurobiol 41: 127-134

Shors TJ, Miesegaes G, Beylin A, Zhao M, Rydel T, Gould E. 2001. Neurogenesis in the adult is involved in the formation of trace memories. Nature 410: $372-375$.

Silva-Gomez AB, Rojas D, Juarez I, Flores G. 2003. Decreased dendritic spine density on prefrontal cortical and hippocampal pyramidal neurons in postweaning social isolation rats. Brain Res 983: 128-136.

Sindreu CB, Scheiner ZS, Storm DR. 2007. Ca2+-stimulated adenylyl cyclases regulate ERK-dependent activation of MSK1 during fear conditioning. Neuron 53: 79-89.

Soloaga A, Thomson S, Wiggin GR, Rampersaud N, Dyson MH, Hazzalin CA, Mahadevan LC, Arthur JSC. 2003. MSK2 and MSK1 mediate the mitogen- and stress-induced phosphorylation of histone H3 and HMG-14. EMBO J 22: 2788-2797. 
Su C, Underwood W, Rybalchenko N, Singh M. 2011. ERK1/2 and ERK5 have distinct roles in the regulation of brain-derived neurotrophic factor expression. J Neurosci Res 89: 1542-1550.

Sugiura H, Tanaka H, Yasuda S, Takemiya T, Yamagata K. 2009. Transducing neuronal activity into dendritic spine morphology: New roles for p38 MAP kinase and N-cadherin. Neuroscientist 15: 90-104.

Sunyer B, Patil S, Hoger H, Lubec G. 2007. Barnes maze, a useful task to assess spatial reference memory in the mice. Nat Protoc 390: 10-38.

Thomas GM, Huganir RL. 2004. MAPK cascade signalling and synaptic plasticity. Nat Rev Neurosci 5: 173-183.

Thomson S, Clayton AL, Hazzalin CA, Rose S, Barratt MJ, Mahadevan LC. 1999. The nucleosomal response associated with immediate-early gene induction is mediated via alternative MAP kinase cascades: MSK1 as a potential histone H3/HMG-14 kinase. EMBO J 18: $4779-4793$.

Vaillant AR, Zanassi P, Walsh GS, Aumont A, Alonso A, Miller FD. 2002. Signaling mechanisms underlying reversible, activity-dependent dendrite formation. Neuron 34: 985-998.

van Praag H, Kempermann G, Gage FH. 2000. Neural consequences of environmental enrichment. Nat Rev Neurosci 1: 191-198.

Wiggin GR, Soloaga A, Foster JM, Murray-Tait V, Cohen P, Arthur JSC. 2002. MSK1 and MSK2 are required for the mitogen- and stress-induced phosphorylation of CREB and ATF1 in fibroblasts. Mol Cell Biol 22: 2871-2881.
Wu J, Rowan MJ, Anwyl R. 2006. Long-term potentiation is mediated by multiple kinase cascades involving CaMKII or either PKA or p42/44 MAPK in the adult rat dentate gyrus in vitro. J Neurophysiol 95: 3519-3527.

Yilmaz-Rastoder E, Miyamae T, Braun AE, Thiels E. 2010. LTP- and LTD-inducing stimulations cause opposite changes in arc/arg3.1 mRNA level in hippocampal area CA1 in vivo. Hippocampus 21: $1290-1301$.

Zagrebelsky M, Holz A, Dechant G, Barde YA, Bonhoeffer T, Korte M. 2005. The p75 neurotrophin receptor negatively modulates dendrite complexity and spine density in hippocampal neurons. J Neurosci 25: 9989-9999.

Zhang W, Liu HT. 2002. MAPK signal pathways in the regulation of cell proliferation in mammalian cells. Cell Res 12: 9-18.

Zhang X, Sullivan JA, Moskal JR, Stanton PK. 2008. A NMDA receptor glycine site partial agonist, GLYX-13, simultaneously enhances LTP and reduces LTD at Schaffer collateral-CA1 synapses in hippocampus. Neuropharmacology 55: 1238-1250.

Zhen X, Du W, Romano AG, Friedman E, Harvey JA. 2001. The p38 mitogen-activated protein kinase is involved in associative learning in rabbits. J Neurosci 21: 5513-5519.

Received January 24, 2012; accepted in revised form July 29, 2012. 


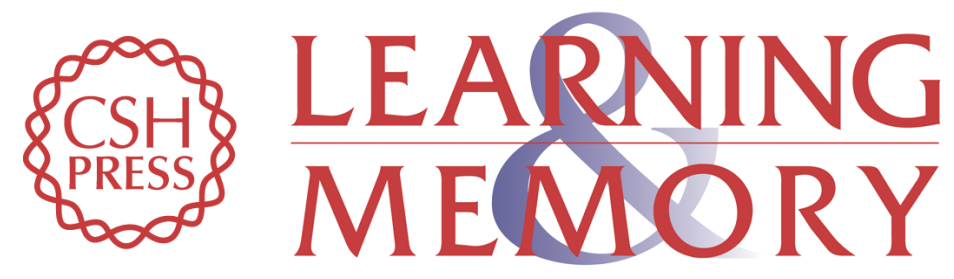

\section{MSK1 regulates environmental enrichment-induced hippocampal plasticity and cognitive enhancement}

Kate Karelina, Katelin F. Hansen, Yun-Sik Choi, et al.

Learn. Mem. 2012, 19:

Access the most recent version at doi:10.1101/lm.025775.112

Supplemental http://learnmem.cshlp.org/content/suppl/2012/10/17/19.11.550.DC1
Material

References This article cites 68 articles, 18 of which can be accessed free at: http://learnmem.cshlp.org/content/19/11/550.full.html\#ref-list-1

License

Email Alerting Receive free email alerts when new articles cite this article - sign up in the box at the Service top right corner of the article or click here. 